\title{
Transdermal Patch Dosage Form
}

National Cancer Institute

\section{Source}

National Cancer Institute. Transdermal Patch Dosage Form. NCI Thesaurus. Code C149996.

Flexible single-dose preparation intended to be applied to the unbroken skin to obtain a systemic delivery over an extended period of time. Transdermal patches consist of a backing sheet supporting a reservoir or a matrix containing the active substance(s) and on the top a pressure-sensitive adhesive, which assures the adhesion of the preparation to the skin. The backing sheet is impermeable to the active substance(s) and normally impermeable to water. In reservoir systems the active substance may be dissolved or dispersed in a semi-solid basis or in a solid polymer matrix, which is separated from the skin by a rate-controlling membrane. The pressure-sensitive adhesive may, in this case, be applied to some or all parts of the membrane, or only around the border of the membrane and the backing sheet. Matrix systems contain the active substance in a solid or semi-solid matrix, the properties of which control the diffusion pattern to the skin. The matrix system may also be a solution or dispersion of the active substance in the pressure-sensitive adhesive. The releasing surface of the patch is covered by a protective liner to be removed before applying the patch to the skin. 